\title{
ANALYSIS ON THE COORDINATED DEVELOPMENT OF URBANIZATION AND ECOLOGICAL ENVIRONMENT OF THE CITY CLUSTER ALONG THE MIDDLE REACHES OF THE YANGTZE RIVER IN CHINA
}

\author{
ZHoU, P. C. ${ }^{1}-$ LI, Y. T. ${ }^{2}-$ YANG, Y. F. $.^{2,3}-$ ZHANG, H. M. ${ }^{1 *}$ \\ ${ }^{1}$ School of Surveying and Urban Spatial Information, Henan University of Urban Construction, \\ Pingdingshan 467036, China \\ ${ }^{2}$ College of Environment and Planning, Henan University, Kaifeng 475004, China \\ ${ }^{3}$ Key Laboratory of Geospatial Technology for Middle and Lower Yellow River Regions, \\ Ministry of Education, Kaifeng 475004, China \\ *Corresponding authors \\ e-mail: yyfnp@henu.edu.cn (Y.F.Yang); $20180101 @$ hncj.edu.cn (H. M. Zhang) \\ (Received $18^{\text {th }}$ Mar 2020; accepted 20 $0^{\text {th }}$ Aug 2020)
}

\begin{abstract}
This paper studies the evolution process of the urbanization and ecological environment level of 28 cities in the city cluster along the middle reaches of the Yangtze River in China from 2007 to 2017 on the scale of city cluster and discusses the coordination relationship between the two. The research found that: (1) During the research period, the urbanization level and the ecological environment level of 28 cities increased significantly. (2) The urbanization is generally at a low level and the spatial imbalance among cities is gradually expanding; the ecological environment is generally at a medium level and the spatial imbalance among cities is gradually decreasing. (3) The center transferring track and the center variation consistency of the urbanization level and the ecological environment level present a changing trend of "reverse direction - same direction", and the overall coordination of the two is gradually enhanced. (4) The spatial coordination between the urbanization level and the ecological environment level is constantly enhanced. The Getis-Ord $\mathrm{Gi}^{*}$ index generally shows a spatial distribution feature of "high in the southeast area and low in the northwest area".
\end{abstract}

Keywords: spatiotemporal differentiation, spatial equilibrium, kernel density estimation, exploratory spatial data analysis, PSR model, center of gravity coordination model

\section{Introduction}

The city cluster area is the strategic core area of national economic development and the main area of national new urbanization which undertakes the historical responsibility of bearing the transfer of the world's economic centers (Fang, 2014). The development of the city cluster not only determines the future of China but also determines the development progress of urbanization in the world (Fang et al., 2015). As a huge engine to promote China's economic and social development, urban agglomerations focus too much on the speed of development in the process of urbanization, resulting in serious environmental problems such as environmental pollution, ecological damage and resource shortage. These problems in turn restrict the development process of urbanization. Coordinating the relationship between urbanization and ecological environment now is a worldwide strategic issue that is widely concerned by the academic circles and the government decision-making departments (Fang et al., 2016; Liang et al., 2019). Statistics show that, at present, China's urban agglomerations discharge more than $67 \%$ of the country's industrial 
waste water, waste gas, solid waste, etc. Although urban agglomerations concentrate more than $3 / 4$ of the total economic output and economic output of the country, at the same time, more than $3 / 4$ of the national pollution output is concentrated, and the environmental pollution problem is becoming increasingly prominent (Fang et al., 2016). According to the prediction of the Chinese Academy of Sciences, in the next 20 years from 2011 to 2030 , it will additionally require 3.2 billion $\mathrm{m}^{3}$ of urban water and $3460 \mathrm{~km}^{2}$ of urban construction land, consume 210 million tons of standard coal and add $2.34 \%$ of ecological overload for every $1 \%$ increase of the urbanization level in China, which are respectively 1.88 times, 3.45 times, 2.89 times and 2.42 times more than those in the past 30 years (1980-2010). Whether these resource and environmental issues can be addressed will directly affect the bright future of China's urbanization development in the next few decades (Fang and Fang, 2013). According to China's urbanization development planning target, the urbanization rate is estimated to reach $65 \%-70 \%$ by 2030 (Hou et al., 2014), which means there will be about $400-500$ million rural people entering the town in the future, and this process is bound to bring huge impacts on the ecological environment. Therefore, the research on the coordinated development of urbanization and ecological environment is not only the hot spot and frontier of international scientific research but also the strategic demand for sustainable development of the city cluster areas in China (Kates et al., 2001; Clark, 2007; Reid et al., 2010).

Objectively, there is an interactive coercing relationship between the urbanization and the ecological environment. With rapid development of the economy, the impact and pressure on the ecological environment brought by urbanization become more obvious, and the constraints and restrictions to the urbanization by ecological environment also become more prominent (Sun et al., 2017; Fang and Yang, 2006). The research on the interactive coupling effect between urbanization and ecological environment in mega-city cluster areas is the frontier and a high-priority theme of the scientific research of the earth system in the next 10 years (Fang et al., 2016). Currently, the research on the coordinated development of urbanization and ecological environment mainly focuses on the following aspects:

(1) Research of theoretical framework. Scholars paid attention to the issue of urban development and ecological environment at an earlier time, but systematic research on the relationship between urbanization and ecological environment mainly began from the middle of the 20th century (Liu et al., 2005a). In 1971, the United Nations Educational, Scientific and Cultural Organization conducted a comprehensive exploration of the relationship between humanity and the natural environment and prepared the "Man and the Biosphere" program, which caused people's widespread concern about environmental pollution. The book Limits to Growth by Meadows predicted "limited growth" about the world's urbanization prospects, which aroused widespread concern about the world's resources and environmental issues caused by urbanization (Sun et al., 2017). B. Ward commented the impact of economic development and environmental pollution on different countries in his book Only One Earth and called on countries to pay attention to the ecological environment and the problems faced by urbanization and industrialization (Wandesforde-Smith and Rosenbaum, 1986); in Goldsmith's Blueprint of Life and West's Cities in Crisis, it comprehensively analyzed and predicted the ecological crisis in the urbanization process and drove related research into diversified fields (Kjellstrom and Corvalan, 1995). Since then, related scholars and institutions have conducted deep research 
closely around topics such as ecological cities and sustainable cities, providing the direction for the study of complex problems in the urbanization process (Lin, 2006; Friedman, 2006; Zhang and Zhao, 2003). Ma and Wang (1984) proposed the idea of complex ecosystem, enriching the theoretical basis of urban ecological research. Wang and Liu (1988) proposed the use of methods like ecosystem cybernetics and general goal planning to study the internal structure and external environment of the ecosystem. Fang et al. (2016) created the theoretical framework of the near and remote interactive coupling effect based on the complex nonlinear coupling relationship between the two. Some scholars have carried out a series of explorations on sustainable development (Yan and Tang, 1984; Yang and Zhu, 1999).

(2) Analysis of the interactive coupling mechanism. Related research studies focus on aspects including key elements of the interactive coercing between urbanization and ecological environment, spatial-temporal evolution features, coupling mechanism and rules and risk diagnosis and evaluation. David J. Rapport and Tony Friend proposed the theoretical framework of "Pressure-State-Response" (PSR) (Berger and Hodge, 1998). Grossman and Krueger discovered the evolution rule of inverted "U"-type relationship between the two, namely the famous Environmental Kuznets Curve (EKC) (CavigliaHarris et al., 2009). York et al. (2003) built a double logarithmic model to describe the relationship between the two. Gu (1994) proposed three models of domestic urbanization and ecological environment. Liu et al. (2005b) revealed the main controlling factors of the interactive coupling and the mutual restraining effect between the two. Huang and Fang (2003) deduced the double exponential curve between the two by fitting the Environmental Kuznets Curve and the logarithmic curve of urbanization, which further enriched the theoretical research.

(3) Technical methods and path research projects. Mainly based on GIS, integrated modeling and big data methods, an integrated spatial-temporal coupling dynamics model is constructed to quantitatively study the interactive coupling effect between the two (Fang et al., 2016). Sultan et al. (1999) used the 3 "S" technology to analyze the pressure of urbanization on the ecological environment of the Nile Delta. Varis and Fraboulet-Jussila (2002) used the neural network model to analyze that the urbanization process aggravated the water resource crisis in the Senegal River basin; Veziroglu and Macário (2014) used the system dynamics model to evaluate the water resource use efficiency under the background of rapid urbanization; Ducrot et al. (2004) simulated the water resource response in the process of urbanization based on the CA model; Saysel et al. (2002) used the gravity model to reveal the mechanism of agricultural land transformation and development under the background of rapid urbanization; Kok et al. (2000) analyzed the dynamic correlation mechanism between urbanization and water resource in Indonesia based on the fuzzy sets theory. Qian and Wang (1995) explored the relationship between the two by means of remote sensing and GIS technology; Shi and Chen (1996) used dynamic simulation system to explore the structure and layout of complex ecosystems; Qiao and Fang (2005) studied the path of coordinated development of them. In general, these studies gradually transformed from qualitative description to quantitative analysis and laid theoretical and practical foundation for the follow-up scholars' research (Sharma et al., 2013; Radhi et al., 2013; Fang and Wang, 2013; Xiong et al., 2012; Lenschow et al., 2016). As to the research contents, scholars mainly explored the relationship between the two under the framework of sustainable development theory, and qualitative analysis was more than quantitative analysis. Regarding the research areas, scholars were mainly concerned in arid areas and 
economically developed areas. The research areas included national, provincial and prefecture-level cities, but there were few research studies on the city cluster and its internal areas.

Based on this, this paper takes the city cluster along the middle reaches of the Yangtze River in China as the research object to build a comprehensive evaluation index system. Firstly, the entropy weight - TOPSIS model was used to evaluate the index value of urbanization and ecological environment system. Then, the kernel density estimation and the spatial barycenter transfer model were used to explore the spatial evolving characteristics and distribution patterns of each system. Finally, we use the coupling coordination model to determine the coordinated development pattern of each system, in order to provide reference for the coordinated sustainable development of urbanization and ecological environment system of urban agglomerations.

The main research objectives of this paper are as follows: (1) Evaluate the comprehensive level of the urbanization and the ecological environment of the city cluster along the middle reaches of the Yangtze River, and understand the development situation of the urbanization level and the ecological environment level. (2) Quantitatively analyze the coordination status of the urbanization and the ecological environment and their spatial distribution features using the coordination level model.

(3) Based on the conclusions of the above theoretical discussion and empirical analysis, propose corresponding countermeasures and suggestions.

\section{Study area, index selection and data sources}

\section{Overview of the study area}

The city cluster along the middle reaches of the Yangtze River is a super large urban agglomeration with Hubei, Hunan and Jiangxi provinces as the main body (Fig. 1). It is located in the middle of the Yangtze River Basin in China, with a total of 31 cities. (In this study, Xiantao City, Qianjiang City and Tianmen City are excluded due to the lack of data. The research unit includes 28 cities.) In 2017, the city cluster along the middle reaches of the Yangtze River has a land area of $326100 \mathrm{~km}^{2}$, a total population of 125 million people, and a GDP of 7.90 trillion yuan, ranking the fifth among the urban agglomerations in China. The per capita GDP was 63205 yuan, 3545 yuan higher than the national average. The level of urbanization is 59\%, 2.5 percentage points higher than that of the whole country. The city cluster along the middle reaches of the Yangtze River accounts for $9.6 \%$ of the total economic volume with $3.4 \%$ land area and $9.0 \%$ population in China. The economic structure of the city cluster along the middle reaches of the Yangtze River is dominated by industry, and the heavy chemical industry is obviously dominant in the industrial system. In 2017, the industrial output value of iron and steel, non-ferrous metallurgy, petrochemical industry, coal mining and electric power, building materials and other energy raw materials accounted for $50 \%$ of the total industrial output value, and the output value of equipment manufacturing industry accounted for $32 \%$ of the total industrial output value. The industrial output value of the industries mentioned above were $82 \%$ of the total industrial output value. Most of the industries are high energy consuming industries, which are the main sources of industrial pollution in urban agglomerations. This urbanization process led by industry not only intensifies the demand for natural resources, but also causes a lot of environmental problems. Therefore, the research on the coordinated relationship 
between urbanization and ecological environment has certain practical significance for the healthy and harmonious development of the region.

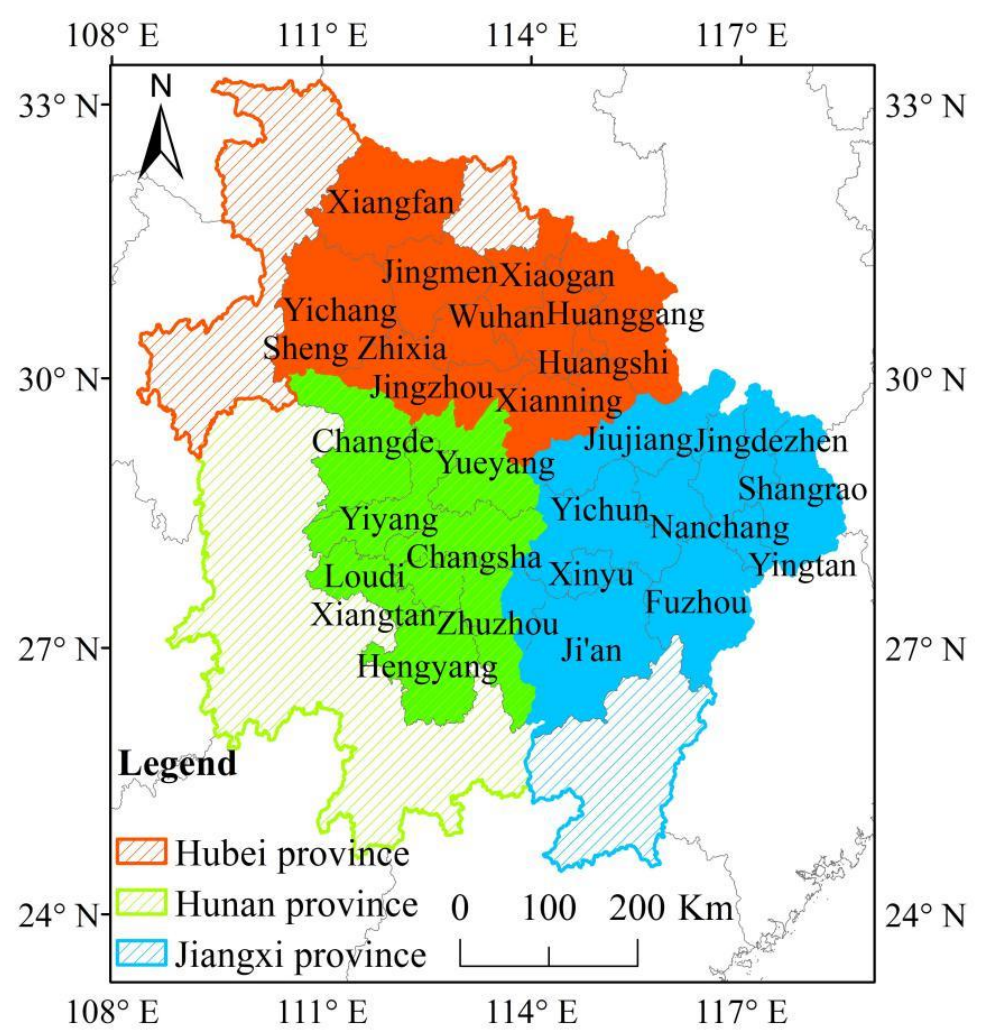

Figure 1. Overview of the study area

\section{Index selection and data sources}

Index selection

Based on the understanding of the meaning, features and functions of urbanization and ecological environment development, with reference to existing researches (Liang et al., 2019; Zhang et al., 2014; Xie et al., 2015), a comprehensive evaluation index system is constructed (Table 1).

\section{Research objects and data sources}

28 cities in the city cluster along the middle reaches of the Yangtze River (excluding the 3 cities of Tianmen, Xiantao and Qianjiang) are selected as the research objects. Three time sections in 2007, 2012 and 2017 are selected in this paper, and the data comes from China Statistical Yearbook, China City Statistical Yearbook, the statistical yearbooks of Hubei Province, Jiangxi Province and Hunan Province.

\section{Research methods}

\section{Measurement of the urbanization level and the ecological environment level}

The entropy weight - TOPSIS model is an improvement of the weight determination method in the traditional TOPSIS evaluation method by using the entropy weight 
method. It has the advantages of practicality and objectivity and has little demand for the sample but the result is reasonable (Ren et al., 2017). In this paper, existing research studies are used for reference (Ren et al., 2017), and the entropy weight - TOPSIS model is adopted to measure the urbanization level and the ecological environment level of the researched area.

Table 1. Evaluation index system for urbanization level and ecological environment level

\begin{tabular}{|c|c|c|c|}
\hline System layer & Criterion layer & Index layer & Index nature \\
\hline \multirow{5}{*}{$\begin{array}{l}\text { Evaluation index system for } \\
\text { urbanization level }\end{array}$} & Basic process & \begin{tabular}{|c|} 
Urban population/total population \\
Non-agricultural employed population/total employed population \\
Non-agricultural output value/GDP \\
Total export-import volume/GDP \\
Foreign direct investment/GDP
\end{tabular} & $\begin{array}{l}+ \\
+ \\
+ \\
+ \\
+\end{array}$ \\
\hline & Economic benefit & $\begin{array}{c}\text { Per capita GDP } \\
\text { Per capita fixed asset investment } \\
\text { Per capita social consumption } \\
\text { Per capita disposable income of residents } \\
\text { Per capita local fiscal revenue }\end{array}$ & $\begin{array}{l}+ \\
+ \\
+ \\
+ \\
+\end{array}$ \\
\hline & $\begin{array}{c}\text { Social } \\
\text { development }\end{array}$ & $\begin{array}{l}\text { Per capita urban park green land area } \\
\text { Hot gas penetration rate } \\
\text { Number of medical beds per } 10,000 \text { people } \\
\text { Urban and rural insurance coverage rate } \\
\text { Number of college students per } 10,000 \text { people }\end{array}$ & $\begin{array}{l}+ \\
+ \\
+ \\
+ \\
+\end{array}$ \\
\hline & $\begin{array}{l}\text { Urban-rural } \\
\text { integration }\end{array}$ & $\begin{array}{c}\text { Urban per capita disposable income } \\
\text { Rural per capita disposable income } \\
\text { Urban-rural consumption ratio } \\
\text { Urban-rural dual structure index }\end{array}$ & $\begin{array}{l}+ \\
+ \\
- \\
-\end{array}$ \\
\hline & $\begin{array}{l}\text { Technology } \\
\text { support }\end{array}$ & $\begin{array}{c}\text { Number of patent grants per } 10,000 \text { people } \\
\text { Per capita postal and telecom services } \\
\text { Per capita science and technology investment } \\
\text { Number of Internet broadband access users per } 10,000 \text { people }\end{array}$ & $\begin{array}{l}+ \\
+ \\
+ \\
+\end{array}$ \\
\hline \multirow{3}{*}{$\begin{array}{l}\text { Evaluation index system for } \\
\text { ecological environment level }\end{array}$} & $\begin{array}{l}\text { Ecological } \\
\text { environment } \\
\text { pressure }\end{array}$ & $\begin{array}{c}\text { Industrial wastewater discharge intensity } \\
\text { Industrial sulfur dioxide discharge intensity } \\
\text { Industrial smoke (dust) discharge intensity } \\
\text { Per capita water consumption } \\
\text { Per capita liquefied petroleum gas consumption } \\
\text { Natural population growth rate } \\
\text { Built-up area/administrative area }\end{array}$ & $\begin{array}{l}- \\
- \\
- \\
- \\
- \\
- \\
-\end{array}$ \\
\hline & $\begin{array}{c}\text { Ecological } \\
\text { environment } \\
\text { situation }\end{array}$ & $\begin{array}{c}\text { Per capita cultivated land area } \\
\text { Per capita water resource } \\
\text { Good or moderate air quality achievement rate in urban area } \\
\text { Forest coverage rate } \\
\text { Per capita park green land area } \\
\text { Per capita industrial sulfur dioxide discharge } \\
\text { Per capita industrial waste water discharge } \\
\text { Per capita industrial solid waste discharge }\end{array}$ & $\begin{array}{l}+ \\
+ \\
+ \\
+ \\
+ \\
- \\
- \\
-\end{array}$ \\
\hline & $\begin{array}{l}\text { Ecological } \\
\text { environment } \\
\text { response }\end{array}$ & $\begin{array}{c}\text { Green coverage rate in built-up areas } \\
\text { Forest plantation area } \\
\text { Comprehensive utilization rate of industrial solid waste } \\
\text { Centralized treatment rate of sewage treatment plant } \\
\text { Decontamination rate of domestic garbage } \\
\text { Unit GDP energy consumption } \\
\text { Number of patent grants per } 10,000 \text { people }\end{array}$ & $\begin{array}{l}+ \\
+ \\
+ \\
+ \\
+ \\
- \\
+\end{array}$ \\
\hline
\end{tabular}




\section{Measurement of imbalance}

This paper uses the kernel density estimation method in Eviews 9.0 software to analyze the kernel density of the urbanization level and the ecological environment level of the researched area (Wang et al., 2018). The estimation formula of kernel density is:

$$
f(x)=\frac{1}{n h} \sum_{i}^{n} \frac{K\left(x_{i}-x\right)}{h}
$$

In the formula: $f(x)$ is a probability density function; $n$ is the number of researched areas, $i=1,2, \ldots, n ; h$ is the bandwidth; $K\left(x_{i}-x\right)$ is the random kernel estimation function.

\section{Measurement of coordination}

\section{(1) Measurement of overall coordination}

In this paper, the center model and the spatial coupling situation of the center are used to reflect the overall coupling situation between the two. The center model is (Zhou et al., 2016):

$$
G_{I}(x, y)=\frac{\sum_{j}^{n} I_{j}\left(Q\left(x_{j}, y_{j}\right)\right)}{\sum_{j}^{n} I_{j}}
$$

In the formula: $G_{I}$ respectively represents the center of the urbanization level and the ecological environment level; $n$ is the number of researched areas; $I_{j}$ is the urbanization level and the ecological environment level of the number $j$ city respectively; $x_{j}$ and $y_{j}$ are respectively the longitude and latitude coordinates of the number $j$ city.

The spatial distribution overlapping and the center variation consistency are used to investigate the spatial coupling situation of the centers of them. Among them, the calculation formula for the spatial distribution overlapping is (Zhou et al., 2016):

$$
S=\sqrt{\left(\Delta x_{G}\right)^{2}+\left(\Delta y_{G}\right)^{2}}
$$

In the formula: $S$ represents the distance between the centers of urbanization level and ecological environment level. $x_{G}$ and $y_{G}$ represent the longitude and latitude of the center; The closer the distance is, the more the overlapping is.

The calculation formula for the center variation consistency is (Zhou et al., 2016):

$$
C=\cos \theta=\frac{\Delta x_{A} \Delta x_{B}+\Delta y_{A} \Delta y_{B}}{\left(\Delta x_{A}^{2}+\Delta y_{A}^{2}\right) \times\left(\Delta x_{B}^{2}+\Delta y_{B}^{2}\right)}
$$

In the formula: $\cos \theta$ represents the $\operatorname{cosine}$ of the vector intersection angle $\theta$ of the displacement of the centers of urbanization level and ecological environment level at this time compared with the centers at the previous time, and the value range is $[-1,1]$. The larger the value is, the more consistent the variation is; $\Delta x$ and $\Delta y$ respectively represent the change value of the longitude and latitude of the center at this time compared with the center at the previous time. 


\section{(2) Measurement of spatial coordination}

A coupling coordination model is constructed in this paper to measure the coupling coordination level between the two (Zhang et al., 2014).

Coupling level. Coupling level is an index reflecting the level of interactive coercing between two (or more) systems. Its function is:

$$
C=\sqrt{F(x) \times G(y) /((F(x)+G(y)) / 2)^{2}}
$$

In the formula: $C$ is coupling level with the value range of $[0,1] ; F(x)$ is the urbanization level. $G(y)$ is the ecological environment level; the larger $C$ is, the better coupling level is.

Coordination level. The coordination level model in which both the development level of the two and the coupling relationship between the two are considered is introduced to measure the coordinated development between the two. Its function is:

$$
\begin{gathered}
T=\alpha F(x)+\beta G(y) \\
D=\sqrt{C \times T}
\end{gathered}
$$

In the formula: $D$ is coordination level; $T$ is the development index. $\alpha$ respectively the contribution share of urbanization; $\beta$ respectively the contribution share of ecological environment. Considering that the status of the two is equally important, take $\alpha=\beta=0.5$.

\section{Exploratory spatial data analysis}

In order to reflect the spatial correlation pattern feature of the spatial coordination of the two, the Arcgis10.2 software is used in this paper. The global Moran's I statistics was used to analyze the overall spatial correlation level in the area and the Getis-Ord Gi ${ }^{*}$ index was used to explore the distribution of local cold and hot spots in regional cities.

The global Moran's I index is calculated as follows:

$$
I=\frac{\sum_{i=1}^{n} \sum_{j=1}^{n} W_{i j}\left(x_{i}-u\right)\left(x_{j}-u\right)}{S^{2} \sum_{i=1}^{n} \sum_{j=1}^{n} W_{i j}} ; S^{2}=\frac{1}{n} \sum_{j=1}^{n}\left(x_{i}-u\right)^{2}
$$

In the formula: the Moran's $I$ index has a value range of $[-1,1] . x_{i}$ and $x_{j}$ are respectively the coordination level value of the city $i$ and $j ; u$ is the average value of coordination level; $W_{i j}$ is the spatial weight matrix. If the city $i$ and $j$ have a common boundary, $W_{i j}$ equals to 1 . If there is no common boundary between the two, $W_{i j}$ equals to 0 .

The Getis-Ord Gi* index is calculated as follows:

$$
G_{i}^{*}=\frac{\sum_{i \neq j} W_{i j} x_{j}}{\sum_{i \neq j} x_{j}}
$$

In the formula: $x_{j}$ is the coordination level value of the city $j$; $W_{i j}$ is the spatial weight matrix. 


\section{Results}

\section{Analysis of the urbanization level and the ecological environment level}

\section{Analysis of the spatial-temporal pattern}

The entropy weight - TOPSIS model are used to perform subjective and objective comprehensive weight determination for the index, and the comprehensive evaluation value of urbanization and ecological environment system was calculated (Fig. 2). In order to explore the difference of the development level of different cities, the natural breaks method is used in this paper to classify the comprehensive level of urbanization and ecological environment of the city cluster along the middle reaches of the Yangtze River in three time sections in 2007, 2012 and 2017 into five levels (Table 2).
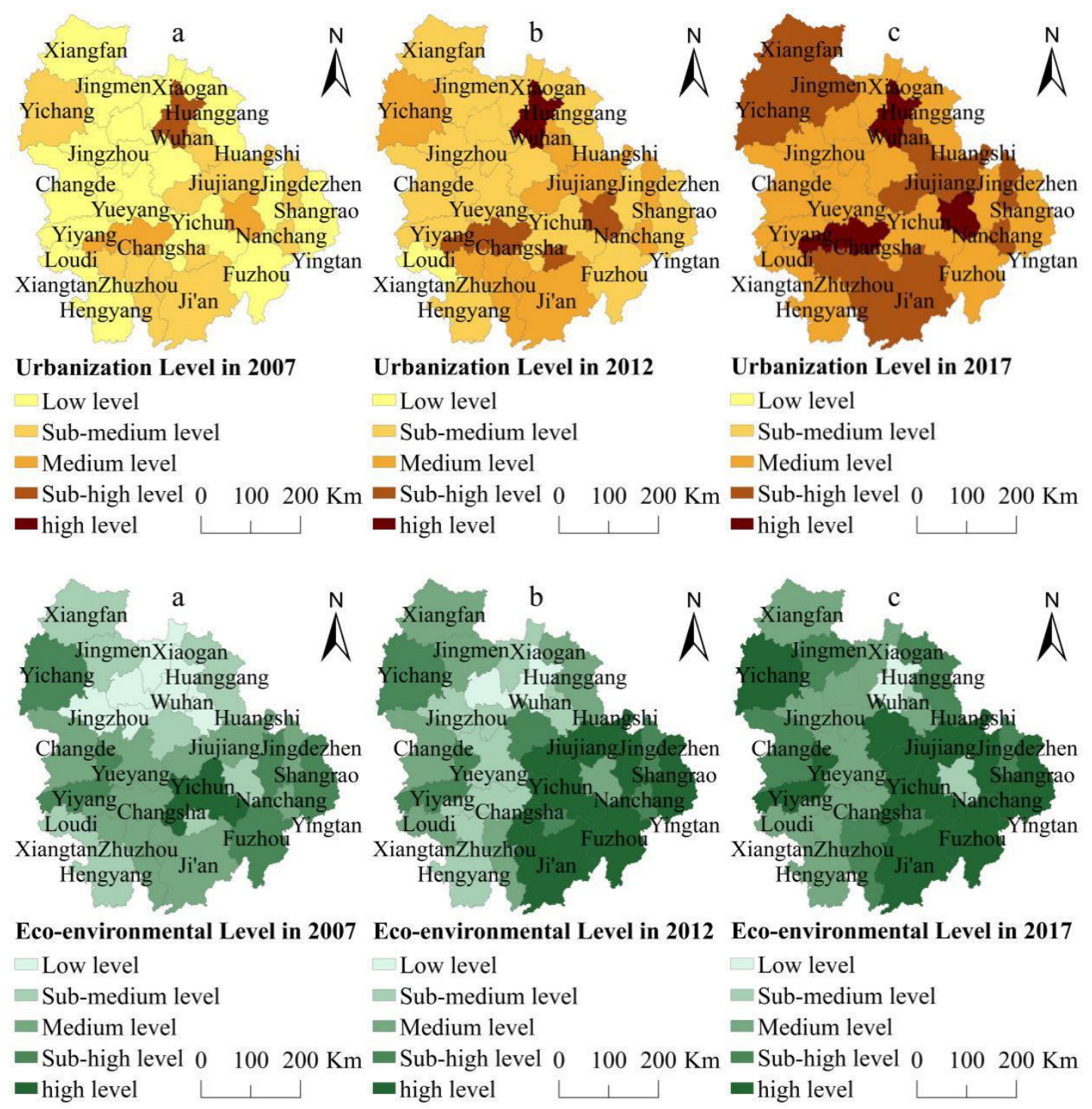

Figure 2. Spatial-temporal evolution of urbanization and ecological environment from 2007 to 2017 
Table 2. Classification criteria for the comprehensive level of urbanization and ecological environment

\begin{tabular}{c|c|c|c|c|c}
\hline Horizontal level & Low level & Sub medium level & Medium level & Sub advanced level & Advanced level \\
\hline Urbanization & $<0.169$ & $0.169-0.228$ & $0.228-0.309$ & $0.309-0.444$ & $0.444<$ \\
Ecological environment & $<0.400$ & $0.400-0.476$ & $0.476-0.526$ & $0.526-0.567$ & $0.567<$ \\
\hline
\end{tabular}

It can be seen from Figure 2 that during the research period, the urbanization level of the city cluster along the middle reaches of the Yangtze River increases significantly. The average urbanization levels in 2007, 2012 and 2017 were respectively $0.178,0.252$, and 0.344 , and there was no city with negative growth of urbanization level. The urbanization level generally shows the spatial pattern of "scattered distribution of highvalue areas and grouped distribution of low-value areas", and the hierarchical structure is relatively stable. The cities with high value mainly include Wuhan, Changsha, Nanchang and Xinyu among which all cities are provincial capital cities except Xinyu. Because the provincial capital city has gathered a large number of economic, policy and talent resources, its urbanization level can continue to improve rapidly. Although the provincial capital city plays a leading role in the province, it also causes the slow development of other cities in the province. The cities with high value basically form three groups which are Yichang - Xiangfan - Jingmen group, Wuhan - Ezhou Huangshi - Jiujiang - Nanchang group and Changsha - Xiangtan - Pingxiang - Zhuzhou - Xinyu - Ji'an group, and there are also some scattered distributed cities such as Jingdezhen and Yingtan. The cities with high value are basically distributed around the provincial capital cities. The urbanization of the cities with middle and low value is basically maintained at the same level, the distribution is strongly concentrated, mainly distributed at the junction of three provinces and the marginal areas of the provinces, and the number of cities with low level cities is gradually decreasing.

The stability of the ecological environment level is not as good as that of the urbanization. There is obvious volatility in most cities, but the volatility is within a reasonable range. In general, the ecological environment level is in an upward trend, and the spatial distribution presenting a distribution pattern of high in the south and east and low in the north and west. The average ecological environment level in 2007, 2012 and 2017 were $0.473,0.516$ and 0.536 respectively. During the research period, cities with high value are mainly distributed in some areas of Jiangxi Province and Hunan Province. The number of cities is gradually increasing, and cities are gathering in the southeast. There are also some scattered distributed cities such as Yichang and Yiyang. The cities at medium level have great variation and are mainly scattered around the cities with high value, especially Yueyang, Changsha and Xiangtan in which the ecological environment levels first decrease and then increase. The development of these cities is highly dependent on natural resources. However, with the continuous emphasis on environmental protection by the country, these cities begin to pay attention to protect the environment in the later development and improve the enterprises with "high pollution, high energy consumption and high water consumption", which makes the ecological environment recovered. The number of cities with low value is small and constantly decreasing, and they are almost distributed around the provincial capital cities of Wuhan and Changsha. In particular, the ecological environment level of the two capital cities of Wuhan and Nanchang is low, indicating that although the urbanization level in these cities is relatively high, 
the ecological environment is under great pressure and the ecological environment protection needs to be strengthened.

\section{Analysis of imbalance}

This paper uses the kernel density estimation method to enter the urbanization level and the ecological environment level of various cities into the Eviews 9.0 software, According to Equation 1, the kernel density distribution of urbanization level and ecological environment level was calculated in 2007, 2012 and 2017 and a kernel density distribution map was drawn (Fig. 3). From Figure 3, it can be seen that: (1) Based on the change trend of the urbanization level: the density curves of 2007, 2012 and 2017 all present a "single peak" distribution, and the level values at peak are 0.16, 0.23 , and 0.32 , respectively. The increase of the level value is within 0.1 , indicating that the urbanization level increases a little and most cities are at low level. The density curves show a change trend from sharp peak to broad peak, the height of the peak decreases and the width increases, indicating that the difference among cities increases and the spatial imbalance is gradually expanding. (2) Based on the change trend of the ecological environment level: the density curve of the ecological environment level presents obvious "double peaks" distribution in 2007, and the level values at peak are 0.36 and 0.48 respectively, indicating that the ecological environment level in 2007 is polarized and there is obvious spatial imbalance. The density curves of 2012 and 2017 present "single peak" distribution, and the level values at peak are 0.50 and 0.57 respectively. The increase of the level value is within 0.1 , indicating that the ecological environment level increases a little and most cities are at medium level. The density curves in 2007 and 2012 present a change trend from "double peaks" to "single peak", the height of the peak decreases and the width increases, indicating that the difference among cities decreases but the spatial imbalance problem is still outstanding. The height of the peak of the density curves in 2012 and 2017 increases and the width decreases, indicating that the ecological environment level of most cities is gradually increasing, and the spatial imbalance is gradually decreasing.

\section{Analysis of the coordinated development pattern of urbanization and ecological environment}

\section{Analysis of overall coordination}

(1) According to Equation 2, the center transferring track of the urbanization level and the ecological environment of cities is calculated (Fig. 4). From Figure 4, it can be seen that both the centers of the urbanization level and the ecological environment level are located in the western area of Jiujiang City. During the research period, the center of the urbanization level moved to the southwest by $2.32 \mathrm{~km}$ first, then moved to the northwest by $15.91 \mathrm{~km}$. In general, it moved to the northwest by $15.38 \mathrm{~km}$, with an average annual moving distance of $1.82 \mathrm{~km}$. The center of the ecological environment first moved to the northeast by $7.03 \mathrm{~km}$, then moved to the northwest by $5.79 \mathrm{~km}$. In general, it moved to the north by $6.80 \mathrm{~km}$, with an average annual moving distance of $1.28 \mathrm{~km}$. Generally, the moving distance of the two centers is relatively short, indicating that the distribution of the two centers is relatively reasonable. The growth of the urbanization level is mainly concentrated in the western and northern parts, especially the rapid development of cities such as Yichang, Xiangfan and Jingmen, and the center generally moves to the northwest. The center of the ecological 
environment is affected by cities such as Yueyang, Changsha and Xiangtan and generally moves towards the north.
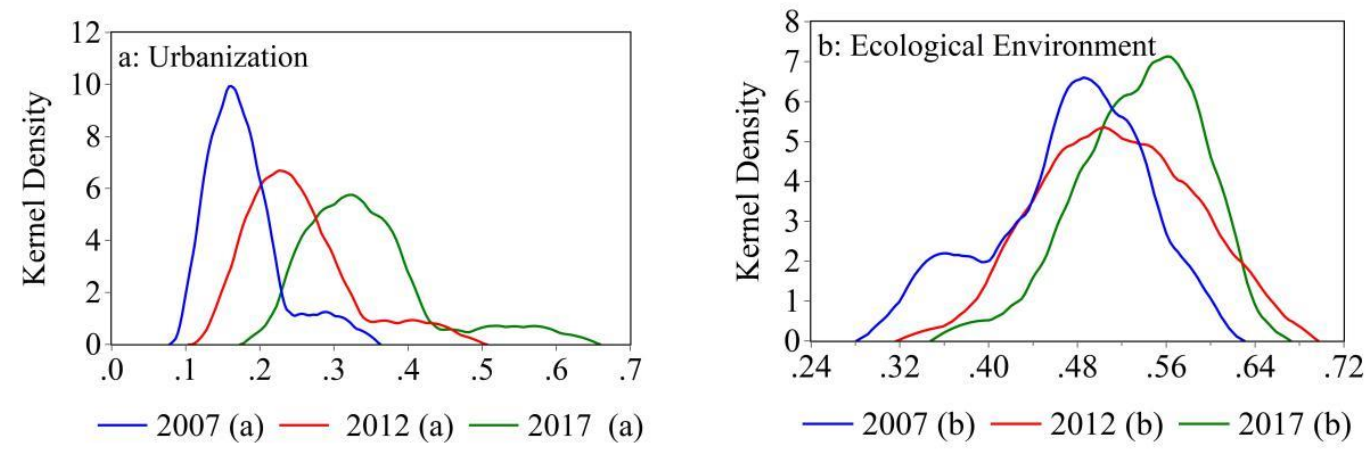

Figure 3. Kernel density distribution of the urbanization level (a) and the ecological environment level $(b)$

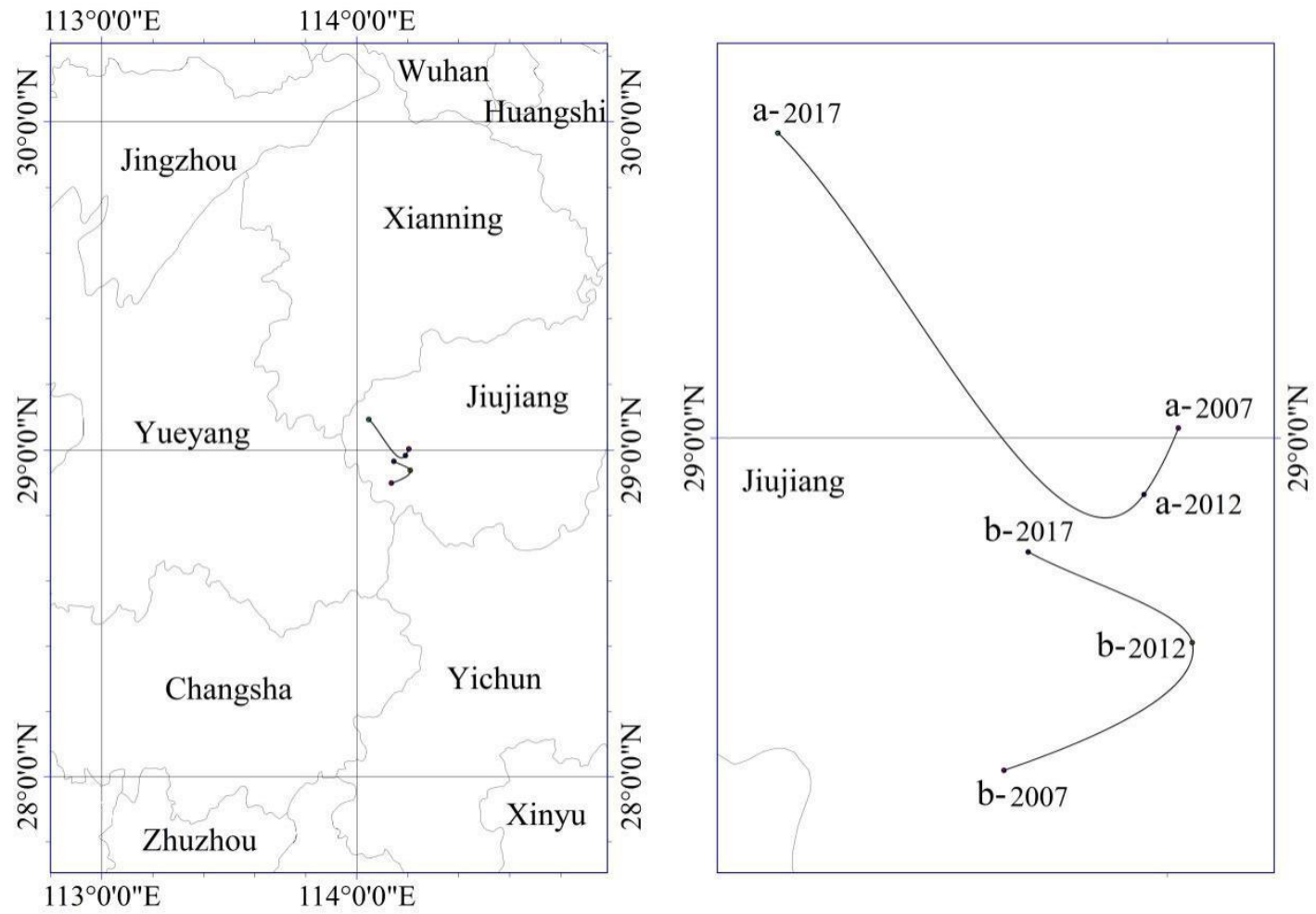

Figure 4. Center transferring track of the urbanization level (a) and the ecological environment level $(b)$

(2) According to Equations 3 and 4, the spatial overlapping (a) and the variation consistency (b) of the urbanization level and the ecological environment level of cities are calculated (Fig. 5). From Figure 5, it can be seen that the distance between the centers of the two presents a change trend of decreasing first and then increasing. It decreased from $11.89 \mathrm{~km}$ in 2007 to $4.82 \mathrm{~km}$ in 2012 and then increased to $15.11 \mathrm{~km}$ in 
2017 , with an average of $10.61 \mathrm{~km}$. In general, the coordination between the two shows a downward trend. The variation consistency of the centers of the two presents an alternate change of "reverse direction - same direction". The variation consistency index increases from -0.88 to 0.96 , which is 0.08 in general, indicating that the movements of the centers of the two are in the same direction and the distance between the centers is in an upward trend.

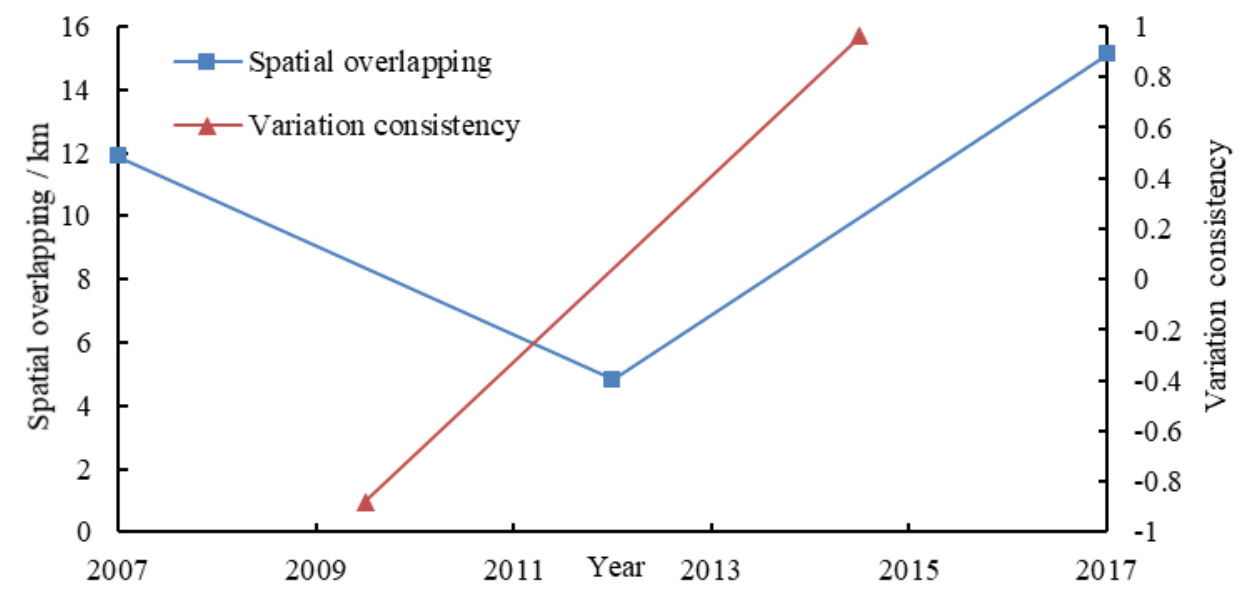

Figure 5. Spatial overlapping and variation consistency of the centers of urbanization level and ecological environment level

\section{Analysis of spatial coordination}

The coordination level between the two is calculated according to Equations 5, 6 and 7 (Fig. 6). According to related researches (Liang et al., 2019), the coordination level is divided into 5 types - serious imbalance $(0<\mathrm{D} \leq 0.2)$, moderate imbalance $(0.2<\mathrm{D} \leq 0.4)$, on the brink of imbalance $(0.4<\mathrm{D} \leq 0.6)$, moderate coordination $(0.6<\mathrm{D} \leq 0.8)$, high coordination $(0.8<\mathrm{D} \leq 1)$. As can be seen from Figure 6, in 2007, only Changsha City was of moderate coordination type, accounting for $3.57 \%$. Other cities were on the brink of imbalance. In 2012, 12 cities were of moderate coordination type, accounting for $42.86 \%$. In 2017, except for Loudi City, other cities were of moderate coordination type, accounting for 96.43\%. On 2007 to 2017, the average growth rate of the coordination level of cities was 22.12\%. The growth rates of 9 cities of Changde, Ezhou, Huanggang, Jingmen, Jingzhou, Xianning, Xiangyang, Xiaogan and Xinyu were above the average, accounting for $32.14 \%$ of the number of researched cities.

In order to further analyze the spatial agglomeration features of the coordination level, the global autocorrelation index of the coordination level is calculated based on Equation 8. The global Moran's I indices of the coordination level in 2007, 2012 and 2017 were $0.278,0.303$ and 0.338 respectively. The normal statistic $\mathrm{z}$ values of the Moran's $I$ in the corresponding year were 3.89, 4.31 and 4.44 respectively. All were greater than the confidence level threshold (1.92), and the $\mathrm{P}$ value was less than 0.05 , passing the significance test, which indicates that there is a relatively strong spatial correlation of the coordination level of cities and the spatial autocorrelation is constantly increasing. 


$$
\text { - } 7894 \text { - }
$$

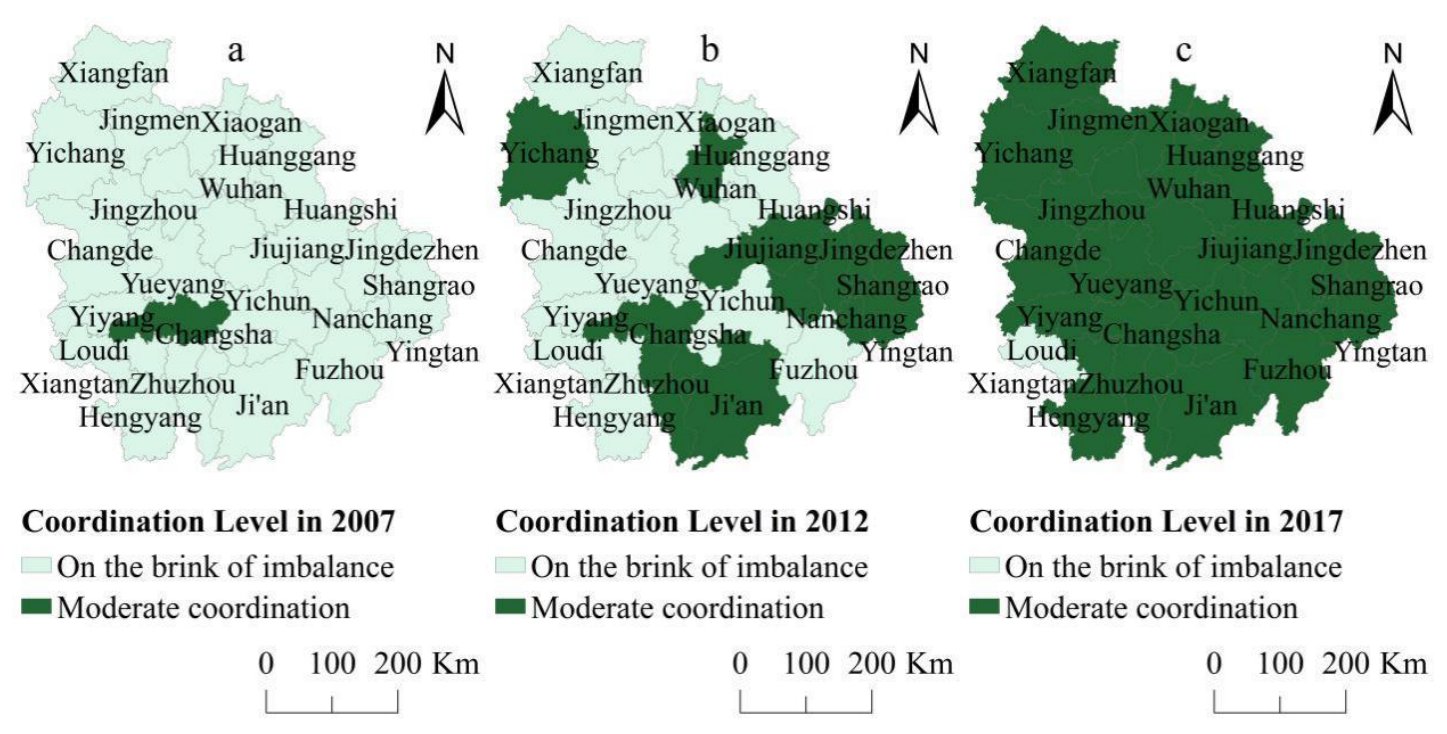

Figure 6. Spatial-temporal evolution of the coordination level on 2007 to 2017

The Getis-Ord $\mathrm{Gi}^{*}$ values of the coordination level in 2007, 2012 and 2017 are calculated based on Equation 9, and it is divided into five types with the Jenks classification method: hot spot area, sub hotspot area, transition area, sub coldspot area and cold spot area (Fig. 7). Generally, the spatial evolution features of the cold and hot spot areas of the coordination level are showed in the following aspects: (1) The GetisOrd $\mathrm{Gi}^{*}$ index of the coordination level generally presents the spatial distribution feature of "high in the southeast area and low in the northwest area". (2) The number of hot spot areas and sub hotspot areas is in the trend of fluctuated rise, the agglomeration scope of high-value areas expands and the agglomeration situation of high-value centers tends to be more prominent, forming a hot spot area with Wuhu City, Xuancheng City and Pingxiang City as the core. (3) During the research period, the number of cold spot areas and sub coldspot areas gradually decreases, the significance level of cold spot areas becomes weak, but the distribution is more concentrated, forming a cold spot area with Chengde and Loudi as the core. (4) During the research period, the hot spot areas present a trend of expansion from the southeast to the northwest of the city cluster, and the cold spot areas present a trend of shrinking to the southwest of the city cluster.

\section{Discussion}

How to prepare a planning program for the coordinated development of urbanization and ecological environment protection is an important issue that needs to be solved for the current new urbanization in China (Fang and Fang, 2013; Liu et al., 2005a). In the rapid urbanization process of the city cluster along the middle reaches of the Yangtze River, the extensive economic development model has triggered a series of ecological and environmental problems. Research on the development model of urbanization and ecological environment system and their coupling effect has become an urgent need of the academic circles and the political circles (Liang et al., 2019; Sun et al., 2017). Taking the city cluster along the middle reaches of the Yangtze River as an example, this paper evaluates the coordination degree and its dynamic spatial-temporal evolution of urbanization and ecological environment by building a coordination degree model. 
The research results can better reflect the actual situation of the region and provide the basis for the formulation of regional development policies. From the research results, we can see that there are two types of change trend of coordination degree between urbanization and ecological environment in the middle reaches of the Yangtze River. One is that with the continuous advancement of urbanization level, the ecological environment will be further damaged, and then collapse, so the overall eco-economic system will also face extinction accordingly; the other is that with the continuous improvement of urbanization level and the increase of the economic aggregate, the city becomes more capable of making environmental protection investment, which will alleviate the ecological pressure to a certain extent, and ultimately help to achieve the coordinated development of the two. This method can also provide reference for the study of the relationship between urbanization and ecological environment in other regions in China.

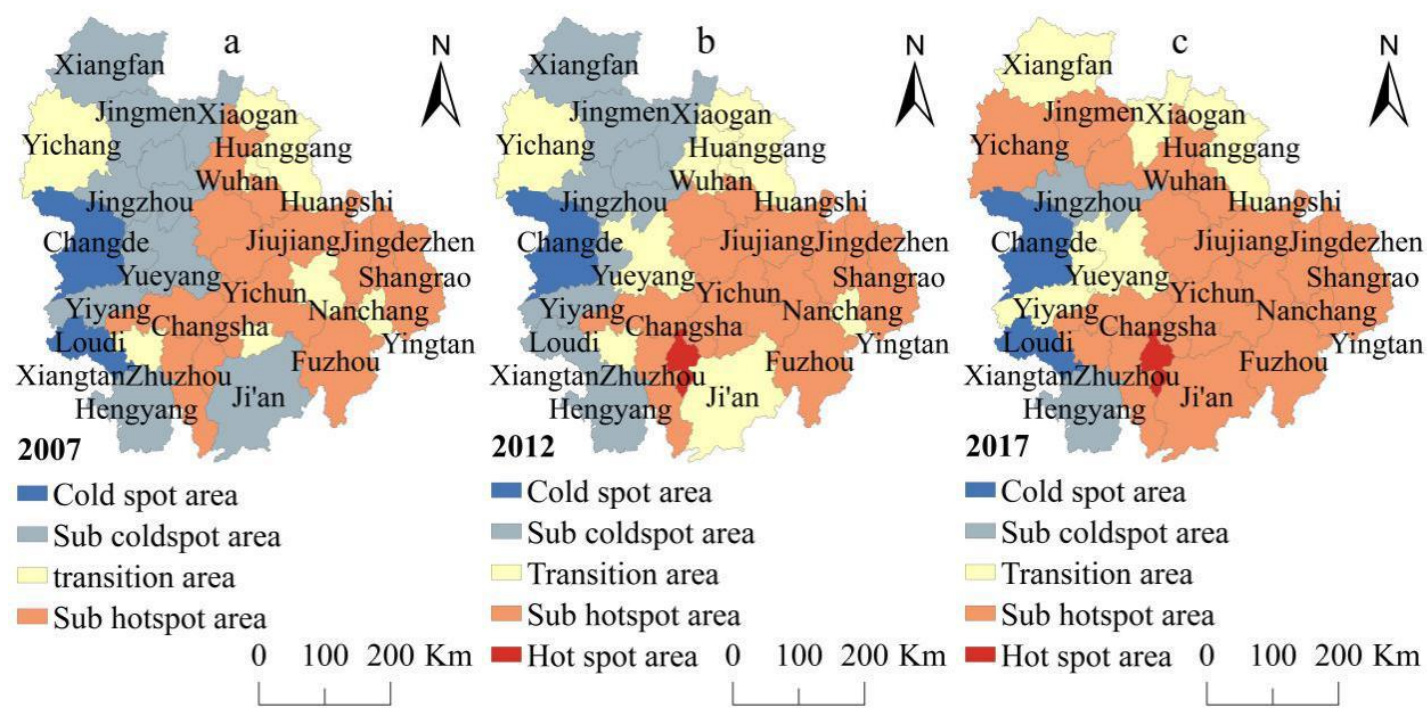

Figure 7. Evolution of hot spots of the coordination level on 2007 to 2017

The major research values of this paper are as follows:

(1) Researching the development level of urbanization and ecological environment and their spatial distribution features of 28 cities in the city cluster along the middle reaches of the Yangtze River has important practical significance for revealing the internal development rules of the interaction between the urbanization and the ecological environment and promoting coordinated development of the two.

(2) The 28 cities in the city cluster along the middle reaches of the Yangtze River belong to three different provinces in administration, and administrative barriers restrict the integration of cities (Sun et al., 2017). Researching the coordination relationship between urbanization and ecological environment can provide some reference for government departments to establish cross-regional coordination organizations at the level of city cluster and to promote integrated development among the regions.

(3) As the strategic core area of national economic development and the main area of national new urbanization, the city cluster area determines the development progress of urbanization in the world (Fang et al., 2016). At present, there is still a lack of research on the coordinated development of urbanization and ecological environment of the city 
cluster along the middle reaches of the Yangtze River. Through empirical analysis in this paper, it provides a reference for the government and related departments to solve the problem of imbalance between urbanization development and ecological environment and enriches the related theoretical research contents.

The shortcomings and prospects are explained in details around the following aspects:

(1) The index system needs to be further supplemented and improved. The contents of the two systems of urbanization and ecological environment are extremely complicated, and there has not yet been a uniform, scientific and comprehensive standard for the establishment of the index system. Therefore, the selection of multisource data (such as the combination of statistical data, remote sensing data and big data, etc.) will be the focus of future research.

(2) In this paper, only three time node data of 10 years are selected. From the perspective of urban development history, the research period is short, which leads to insufficient discussion on the dynamic evolution characteristics and laws of the coordination between urbanization and ecological environment. In the future, with the support of effective data, it is still necessary to conduct further research in a longer period of time, so as to provide more scientific decision-making basis for comprehensive regulation and sustainable development of cities.

(3) In this paper, the factors which affect the coordination of urbanization and ecological environment is not explored and studied, which is a shortcoming of this paper and also it is a problem to be studied and solved in the future.

\section{Conclusion}

This paper studies the evolution process of urbanization level and ecological environment system level of the city cluster along the middle reaches of the Yangtze River from 2007 to 2017 on the scale of city cluster and discusses the coordination relationship between the two. It is found in the research that:

(1) During the research period, the urbanization level and the ecological environment level of the city cluster along the middle reaches of the Yangtze River increased significantly. The urbanization level generally shows the spatial pattern of "scattered distribution of high-value areas and grouped distribution of low-value areas". The spatial distribution of the ecological environment level presenting a distribution pattern of high in the south and east and low in the north and west.

(2) The analysis of imbalance shows that the urbanization level of most cities is relatively low, the difference among cities is increasing, and the spatial imbalance is gradually expanding. The ecological environment of most cities is at a medium level, the difference among cities is decreasing, and the spatial imbalance is gradually decreasing.

(3) The center transferring track and the center variation consistency of the urbanization level and the ecological environment level show a change trend of "reverse direction - same direction". The distance between the centers of the two decreases first and then rises, and the overall coordination gradually increases.

(4) The coordination of the urbanization level and the ecological environment level of the 28 cities is continuously increasing. The Getis-Ord Gi* index of the coordination generally presents a spatial distribution feature of "high in the southeast area and low in 
the northwest area". The hot spot areas expand from the southeast to the northwest of the city cluster, and the cold spot areas shrink to the southwest of the city cluster.

Based on the current situation of the coordinated development of urbanization and ecological environment in the middle reaches of the Yangtze River, and according to the construction requirements of "ecological civilization city", this paper puts forward the following suggestions on how to realize the coordinated development:

(1) Accelerate the development of urbanization, and make full use of ecological environment resources, and gradually realize the synchronous development of the two. On the one hand, timely adjust the less advanced industries, actively adopt energysaving and environment-friendly technologies to transform traditional industries, give priority to the development of low-carbon environment-friendly industries, continuously improve the use rate of clean energy, and promote green urbanization (Liu et al., 2005b; Huang and Fang, 2003). On the other hand, vigorously exploit the connection role of "Internet + " in urban construction, make full use of information technology such as Internet of Things, cloud computing and big data, promote information sharing and business coordination, and improve urban management level and efficiency to make the living environment better (Ren et al., 2017).

(2) These 28 cities need to take different development paths according to their own urban development characteristics. Cities with lagging ecological environment need to reduce pollution emissions and avoid the destruction of the original ecosystem. Cities with lagging urbanization level need to develop high-quality urbanization development path from population, economy, society and space on the premise of ensuring ecological environment security.

(3) The coordinated development of urbanization and ecological environment is the result jointly promoted by mechanisms including population agglomeration and resource utilization, economic operation and structural transformation, urban civilization and technological innovation and policy regulation and guarantee (Fang et al., 2016). On the one hand, mobilize all the people to participate in the construction of ecological civilization, cultivate residents to take a diligent and economical, green and low-carbon lifestyle, encourage the people to actively exercise the right to supervise, report and sue against behaviors which cause environmental pollution, and speed up the construction of ecological civilization (Wang et al., 2018). On the other hand, strengthen the government's comprehensive coordination function in guiding urban development and ecological protection. Learn from the successful experience of developed countries and promote urbanization construction with a global perspective to form an important support for the benign interaction between urbanization and ecological environment (Fang et al., 2016).

Acknowledgments. The authors would like to thank the editors and the anonymous reviewers for their constructive comments and suggestions, which greatly helped to improve the quality of the manuscript.

Author contributions. Pengchao Zhou and Yongfang Yang conceived and designed the research, Pengchao Zhou, Hongmin Zhang analyzed the data; Yongfang Yang and Yating Li revised the manuscript of this study; and Pengchao Zhou wrote the paper. All authors read and approved the final manuscript.

Funding. This research was funded by the National Natural Science Foundation of China, grant number 41601120; Humanity and Social Science Youth foundation of Ministry of Education of China (15YJC790049); Soft Science Project of Henan Science and Technology Development Plan, grant number 182400410202; Key Scientific Research Projects of Higher Education Institutions in Henan 
Province, grant number 18B170002 and Research Topics of Henan Federation of Social Sciences, grant number SKL-2019-3023.

Conflict of interests. The authors declare no conflict of interests.

\section{REFERENCES}

[1] Berger, A. R., Hodge, R. A. (1998): Natural change in the environment: a challenge to the pressure-state-response concept. - Social Indicators Research 44(2): 255-265.

[2] Caviglia-Harris, J. L., Chambers, D., Kahn, J. R. (2009): Taking the "u" out of Kuznets: a comprehensive analysis of the EKC and environmental degradation. - Ecological Economics 68(4): 1149-1159.

[3] Clark, W. C. (2007): Sustainability Science: A Room of Its Own. - In: Schekman, R. (ed.) Proceedings of the National Academy of Sciences of the United States of America. National Academy of Sciences, Washington, DC.

[4] Ducrot, R., Page, C. L., Bommel, P., Kuper, M. (2004): Articulating land and water dynamics with urbanization: an attempt to model natural resources management at the urban edge. - Computers, Environment and Urban Systems 28(1-2): 85-106.

[5] Fang, C. L. (2014): Progress and the future direction of research into urban agglomeration in China. - Acta Geographica Sinica 69(8): 1130-1144.

[6] Fang, C. L., Fang, J. W. (2013): Research on the bottleneck of resources environment in rapid urbanization. - China National Conditions and Strength 4: 33-34.

[7] Fang, C., Wang, J. (2013): A theoretical analysis of interactive coercing effects between urbanization and eco-environment. - Chinese Geographical Science 23(2): 147-162.

[8] Fang, C. L., Yang, Y. M. (2006): Basic laws of the interactive coupling system of urbanization and ecological environment. - Arid Land Geography 29(1): 1-8.

[9] Fang, C. L., Mao, Q. Z., Ni, P. F. (2015): Discussion on the scientific selection and development of China's urban agglomerations. - Acta Geographica Sinica 70(4): 515527.

[10] Fang, C. L., Liu, H. M., Li, G. D. (2016a): International progress and evaluation on interactive coupling effects between urbanization and the eco-environment. - Journal of Geographical Sciences 26(8): 1081-1116.

[11] Fang, C. L., Zhou, C. H., Gu, C. L., Chen, L. D., Li, S. C. (2016b): Theoretical analysis of interactive coupled effects between urbanization and eco-environment in mega-urban agglomerations. - Acta Geographica Sinica 71(4): 531-550.

[12] Friedman, J. (2006): Four theses in the study of China's urbanization. - International Journal of Urban and Regional Research 30(2): 440-451.

[13] Gu, C. L. (1994): On research direction of Chinese urban continued development. Urban Planning Forum 6: 1-9.

[14] Hou, P., Yang, Q. Y., He, J., Min, J. (2014): Analysis of coupling degree between urbanization and ecological environment: a case of 38 districts in Chongqing. - Journal of Southwest China Normal University (Natural Science Edition) 39(2): 81-87.

[15] Huang, J. C., Fang, C. L. (2003): Analysis of coupling mechanism and rules between urbanization and Eco-environment. - Geographical Research 22(2): 211-220.

[16] Kates, R. W., Clark, W. C., Corell, R., Hall, J. M., Jaeger, C. C., Lowe, I., et al. (2001): Environment and development: sustainability science. - Science 292(5517): 641-642.

[17] Kjellstrom, T., Corvalan, C. (1995): Framework for the development of environmental health indicators. - World Health Statistics Quarterly. Rapport Trimestriel de Statistiques Sanitaires Mondiales 48(2): 144-154.

[18] Kok, J. L. D., Titus, M., Wind, H. G. (2000): Application of fuzzy sets and cognitive maps to incorporate social science scenarios in integrated assessment models: a case study of urbanization in Ujung Pandang, Indonesia. - Integrated Assessment 1(3): 177188 . 
[19] Lenschow, A., Newig, J., Challies, E. (2016): Globalization's limits to the environmental state? Integrating telecoupling into global environmental governance. - Environmental Politics 25(1): 136-159.

[20] Liang, L. W., Wang, Z. B., Fang, C. L., Sun, Z. (2019): Spatiotemporal differentiation and coordinated development pattern of urbanization and the ecological environment of the Beijing-Tianjin-Hebei urban agglomeration. - Acta Ecologica Sinica 39(4): 12121225 .

[21] Lin, G. C. S. (2006): Peri-urbanism in globalizing China: a study of new urbanism in Dongguan. - Eurasian Geography and Economics 47(1): 28-53.

[22] Liu, Y. B., Li, R. D., Song, X. F. (2005a): Summary and comment of the correlation study of urbanization and urban Eco-environment. - China Population, Resources and Environment 15(3): 55-60.

[23] Liu, Y. B., Li, R. D., Song, X. F. (2005b): Grey Associative analysis of regional urbanization and eco-environment coupling in China. - Acta Geographica Sinica 60(2): 237-247.

[24] Ma, S. J., Wang, R. S. (1984): The social-economic-natural complex ecosystem. - Acta Ecologica Sinica 4(1): 1-9.

[25] Qian, L. X., Wang, Q. (1995): The impact of RS and GIS supported urban green coverage on Sustainable Urban Development. - Areal Research and Development 4: 14-16.

[26] Qiao, B., Fang, C. L. (2005): The dynamic coupling model of the harmonious development between urbanization and eco-environment and its application in arid area. Acta Ecologica Sinica 25(11): 3003-3009.

[27] Radhi, H., Fikry, F., Sharples, S. (2013): Impacts of urbanization on the thermal behavior of new built up environments: a scoping study of the urban heat island in Bahrain. Landscape and Urban Planning 113: 47-61.

[28] Reid, W. V., Chen, D., Goldfarb, L., Hackmann, H., Lee, Y. T., Mokhele, K., et al. (2010): Earth system science for global sustainability: grand challenges. - Science 330(6006): 916-917.

[29] Ren, Y. F., Fang, C. L., Lin, X. Q. (2017): Evaluation of eco-efficiency of four major urban agglomerations in eastern coastal area of China. - Acta Geographica Sinica 72(11): 129-145.

[30] Saysel, A. K., Barlas, Y., Yenigün, O. (2002): Environmental sustainability in an agricultural development project: a system dynamics approach. - Journal of Environmental Management 64(3): 247-260.

[31] Sharma, R., Ghosh, A., Joshi, P. K. (2013): Analysing spatio-temporal footprints of urbanization on environment of Surat city using satellite-derived bio-physical parameters. - Geocarto International 28(5): 420-438.

[32] Shi, Z. M., Chen, T. (1996): Research advance of urbanization and its effect on urban eco-environment. - Chinese Journal of Ecology 1: 35-41.

[33] Sultan, M., Fiske, M., Stein, T., Gamal, M., Hady, Y. A., Araby, H. E., et al. (1999): Monitoring the urbanization of the Nile Delta, Egypt. - AMBIO A Journal of the Human Environment 28(7): 628-631.

[34] Sun, H. P., Huang, Z. F., Xu, D. D., Shi, X. Y., Liu, H., Tan, L. J., et al. (2017): The spatial characteristics and drive mechanism of coupling relationship between urbanization and eco-environment in the Pan Yangtze River Delta. - Economic Geography 37(2): 165170.

[35] Varis, O., Fraboulet-Jussila, S. (2002): Water resources development in the lower Senegal River basin: conflicting interests, environmental concerns and policy options. International Journal of Water Resources Development 18(2): 245-260.

[36] Veziroglu, A., Macário, Rosário. (2014): A system dynamics model for the reduction of health expenditures through transition to hydrogen vehicles (Srth): case studies in the USA, China, and India. - International Journal of Green Energy 11(7): 695-726. 
[37] Wandesforde-Smith, G., Rosenbaum, W. A. (1986): Environmental politics and policy. The American Political Science Review 80(2): 679-681.

[38] Wang, G., Li, S. J., Ma, Q. F. (2018): Spatial equilibrium and pattern evolution of ecological civilization construction efficiency in China. - Acta Geographica Sinica 73(11): 150-161.

[39] Wang, R. S., Liu, J. G. (1988): The principle of ecological bank and its role in urban ecology research. - Urban Environment \& Urban Ecology 1(2): 20-25.

[40] Xie, Y. C., Gong, J., Zhang, L. L. (2015): Dynamics of Landscape Ecological Security Based on PSR Model in the Bailongjiang River Watershed. - Scientia Geographica Sinica 35(6): 790-797.

[41] Xiong, Y., Huang, S., Chen, F., Ye, H., Wang, C., Zhu, C. (2012): The impacts of rapid urbanization on the thermal environment: a remote sensing study of Guangzhou, South China. - Remote Sensing 4(12), 2033-2056.

[42] Yan, C. M., Tang, J. Z. (1984): Urbanization and urban eco-environment in Shanghai. Journal of East China Normal University (Natural Science) 1: 71-76.

[43] Yang, H., Zhu, L. B. (1999): Seeking ecological supporting on urban sustainable development--Theories on urban ecological supporting system. - Ecologic Science 18(4): 48-52.

[44] York, R., Rosa, E. A., Dietz, T. (2003): STIRPAT, IPAT and ImPACT: analytic tools for unpacking the driving forces of environmental impacts. - Ecological Economics 46(3): 351-365.

[45] Zhang, L., Zhao, S. (2003): Reinterpretation of China's under-urbanization: a systemic perspective. - Habitat International 27(3): 459-483.

[46] Zhang, J. Q., Wu, Y. J., Ge, Y., Wang, C. H., Kung, K. (2014): Eco-security assessments of poor areas based on gray correlation model: a case study in Enshi. - Geographical Research 33(8): 1457-1466.

[47] Zhou, Y., Huang, X. J., Xu, G. L., Li, J. B. (2016): The coupling and driving forces between urban land expansion and population growth in Yangtze River Delta. Geographical Research 35(2): 313-324. 